\title{
Trafficking of AMPA Receptors at Plasma Membranes of Hippocampal Neurons
}

\author{
Jung-Hwa Tao-Cheng, ${ }^{1}$ Virginia T. Crocker, ${ }^{1}$ Christine A. Winters, ${ }^{2}$ Rita Azzam, ${ }^{1}$ John Chludzinski, ${ }^{2}$ \\ and Thomas S. Reese ${ }^{2}$ \\ ${ }^{1}$ Electron Microscopy Facility, and ${ }^{2}$ Laboratory of Neurobiology, National Institute of Neurological Disorders and Stroke, National Institutes of Health, \\ Bethesda MD 20892
}

The number of AMPA receptors at synapses depends on receptor cycling. Because receptors diffuse rapidly in plasma membranes, their exocytosis and endocytosis need not occur near synapses. Here, pre-embedding immunogold electron microscopy is applied to dissociated rat hippocampal cultures to provide sensitive, high-resolution snapshots of the distribution of surface AMPA receptors in spines, dendrites, and cell bodies that will be informative about trafficking of AMPA receptors. The density of the label for GluR2 varies, but is consistent throughout cell body and dendrites in each individual neuron, except at postsynaptic densities (PSDs), where it is typically higher. Glutamate receptor 2 (GluR2) labels at PSDs significantly increase after synaptic activation by glycine treatment and increase further upon depolarization by high $\mathrm{K}^{+}$. Islands of densely packed labels have consistent size and density but vary in frequency under different experimental conditions. These patches of label, which occur on plasma membranes of cell bodies and dendrites but not near PSDs, are taken to be the aftermath of exocytosis of AMPA receptors. A subpopulation of clathrin-coated pits in cell bodies and dendrites label for GluR2, and the number and amount of label in individual pits increase after NMDA treatment. Coated pits near synapses typically lack GluR2 label under basal conditions, but $\sim 40 \%$ of peri-PSD pits label for GluR2 after NMDA treatment. Thus, exocytosis and endocytosis of AMPA receptors occur mainly at extrasynaptic locations on cell bodies and dendrites. Receptors are not preferentially exocytosed near PSDs, but may be removed via endocytosis at peri-PSD locations after activation of NMDA receptors.

\section{Introduction}

Glutamatergic synapses mediate excitatory synaptic transmission in the vertebrate CNS. One subtype of glutamate receptor, the AMPA receptor (AMPAR), mediates fast transmission, and its regulation underlies synaptic efficacy (Malinow and Malenka, 2002). Trafficking of AMPA receptors has been studied by livecell observation of fluorescent-labeled receptors to track their exocytosis, internalization, and lateral diffusion (Groc et al., 2007; Hirling, 2009; Jaskolski and Henley, 2009; Choquet, 2010). The picture emerges that exocytosis of AMPA receptors occurs at somas and dendrites (Yudowski et al., 2007; Jaskolski et al., 2009; Lin et al., 2009; Makino and Malinow, 2009; Araki et al., 2010), and perhaps at spines (Kennedy et al., 2010). Lateral diffusion of AMPA receptors occurs throughout the neuronal surface (Adesnik et al., 2005; Ashby et al., 2006; Makino and Malinow, 2009), except that their mobility is lower at the postsynaptic density (PSD) (Choquet, 2010). Endocytosis of AMPA receptors occurs in the dendritic shafts (Ehlers, 2000; Ashby et al., 2004) and somas (Lin and Huganir, 2007), and also in spines (Kennedy et al.,

Received Sept. 9, 2010; revised Jan. 9, 2011; accepted Jan. 22, 2011.

This work was supported by National Institute of Neurological Disorders and Stroke intramural funds. We thank Dr. Ayse Dosemeci for helpful discussions, and Drs. Paul E. Gallant and Carolyn Smith for critical reading of the manuscript.

Correspondence should be addressed to Thomas $S$. Reese, National Institutes of Health, 49 Convent Drive, Room 3A60, MSC 4477, Bethesda, MD 20892. E-mail: treese@mbl.edu.

DOI:10.1523/JNEUROSCI.4745-10.2011

Copyright $\odot 2011$ the authors $\quad 0270-6474 / 11 / 314834-10 \$ 15.00 / 0$
2010). However, it is not clear how prevalent exocytosis and endocytosis of AMPA receptors are in spines.

Immunogold labeling by electron microscopy (EM) provides higher resolution AMPA receptor localization (Kharazia et al., 1996; Bernard et al., 1997; Nusser et al., 1998; Takumi et al., 1999; Ganeshina et al., 2004), and demonstrates increases in AMPA receptors at PSDs after long-term potentiation (Moga et al., 2006) and acute stimulation (Popratiloff et al., 1998; Larsson and Broman, 2008). Most previous EM studies use the postembedding immunolabeling method, which provides an accurate picture at locations, such as the PSD, with high density of antigen (Nusser et al., 1998; Masugi-Tokita and Shigemoto, 2007). However, postembedding labeling so far has yielded little information about the distributions of receptors present at lower density throughout neuronal membranes, other than those at PSDs. EM evidence is also inconclusive regarding exocytosis of AMPA receptors (Petralia et al., 2003; Gerges et al., 2006), and sparse with respect to their endocytosis (Petralia et al., 2003).

Here we map the distribution of surface AMPA receptors with the increased sensitivity provided by pre-embedding immunogold labeling (Bernard et al., 1997). An antibody to the extracellular domain of glutamate receptor 2 (GluR2), the most prevalent subunit in AMPA receptors (Wenthold et al., 1996), illustrates their distribution in dissociated cultures of hippocampal neurons under different stimulation protocols including conditions that induce AMPA receptor exocytosis, such as added glycine or high $\mathrm{K}^{+}$, and ones that induce AMPA receptor endocytosis, such as added NMDA. The GluR2 label on spine heads is analyzed in 
serial thin sections, and GluR2 labels at PSDs and at somal plasma membranes is measured in single sections. Evidence is presented that exocytosis of AMPA receptors is a unitary event occurring at different frequencies under different experimental conditions. Distributions of clathrin-coated pits labeled for GluR2, indicative of endocytosis of AMPA receptors, are characterized in somal plasma membranes and near PSDs. We thus provide detailed snapshots of the distribution of AMPA receptors at rest and under various stimulation conditions.

\section{Materials and Methods}

\section{Treatment of dissociated hippocampal cultures}

Hippocampal cells from 21-d-old embryonic Sprague Dawley rats (mixed gender) were dissociated and grown on top of a feeder layer of glial cells for 19-26 d (Dosemeci et al., 2001). Culture dishes for experiments were placed on a floating platform in a water bath maintained at $37^{\circ} \mathrm{C}$. Cultures were washed once with Krebs'-Ringer's solution $(124 \mathrm{~mm}$ $\mathrm{NaCl}, 2 \mathrm{~mm} \mathrm{KCl}, 1.24 \mathrm{~mm} \mathrm{KH}_{2} \mathrm{PO}_{4}, 1.3 \mathrm{~mm} \mathrm{MgCl}_{2}, 2.5 \mathrm{~mm} \mathrm{CaCl}_{2}$, and 30 mM glucose in 25 mM HEPES at pH 7.4), treated with (1) Krebs'-Ringer's solution for 2-5 min (control); (2) glycine $(200 \mu \mathrm{M})$ without $\mathrm{Mg}^{2+}$, and with strychnine ( $1 \mu \mathrm{M}$ ) for $3 \mathrm{~min}$; (3) NMDA [20-30 $\mu \mathrm{M}$, with or without TTX (1 $\mu \mathrm{M})$, glycine $(10 \mu \mathrm{M})$, and low $\mathrm{Mg}(0.3 \mathrm{mM})]$ for 2-5 min; or (4) high $\mathrm{K}^{+}$medium $\left(90 \mathrm{~mm} \mathrm{~K}{ }^{+}, \mathrm{NaCl}\right.$ concentration correspondingly reduced) for $2 \mathrm{~min}$ and fixed immediately after treatment. Other cultures were treated for $2 \mathrm{~min}$ in high $\mathrm{K}^{+}$followed by four washes in KrebsRinger's solution and fixed after a total recovery time of $30 \mathrm{~min}$. With samples fixed with no treatment, the culture medium was replaced with fixative immediately after cultures were removed from the incubator.

\section{Pre-embedding immunocytochemistry}

Cultures were fixed with $4 \%$ paraformaldehyde (EMS) in PBS for 30-45 min, or with $1-2 \%$ acrolein (Sigma) in PBS for $1-2$ min, followed by $4 \%$ paraformaldehyde in PBS for $30 \mathrm{~min}$. After fixation, samples were thoroughly washed in PBS, and were either left unpermeabilized to label surface receptors, or to label both surface and internal receptors, or were permeabilized with either $50 \%$ ethanol in water for $10-15$ min or $0.1 \%$ saponin for 40-60 min. Samples were then washed in PBS and incubated with primary antibody against the AMPAR subunit GluR2 (clone 6C4, amino acids 175-430, Millipore Bioscience Research Reagents; Western analysis provided at 1:100) for 1-2 $\mathrm{h}$. Secondary antibody conjugated with Nanogold (Nanoprobes; at 1:150-250) was applied for 1-2 h, then samples were silver enhanced (HQ kit, Nanoprobes) and finally embedded in epoxy resin for thin sectioning as previously described (TaoCheng, 2006). Controls for immunolabeling included withholding the primary antibody and comparing labeling with that from other primary antibodies such as mouse monoclonal anti-clathrin (clone X22, ABR; at 1:250-500), mouse monoclonal anti-transferrin receptor (TfR) (clone OX-26, Millipore Bioscience Research Reagents; at 1:250-500), and mouse monoclonal anti-calmodulin-dependent protein kinase II (CaMKII) [clone 6G9 (2), Millipore Bioscience Research Reagents; at 1:100].

Specificity of the GluR2 antibody is further verified by the absence of labeling on glial plasma membranes (supplemental Fig. $1 A$, available at www.jneurosci.org as supplemental material). Intracellular labeling was highest in the lumen of endoplasmic reticulum (ER) (supplemental Fig. $1 B$, available at www.jneurosci.org as supplemental material), the expected orientations of the $\mathrm{N}$-terminal epitope, and is consistent with AMPA receptors being synthesized and highly concentrated in the ER (for review, see Bassani et al., 2009). However, the amount of intracellular localization of this particular antibody in other organelles with lower concentrations of GluR2 may be underestimated because immunolabeling reagents have to pass through two layers of membrane to reach the antigen inside the lumen. The present study, however, focuses on surface labeling of GluR2.

\section{Morphometry}

Excitatory synapses are identified by the following: (1) characteristic asymmetric (Peters et al., 1991) PSD beneath the postsynaptic membrane; (2) parallel apposition of the presynaptic and postsynaptic mem-
Table 1. Density of GluR2 label derived from serial sections

\begin{tabular}{lll}
\hline & $2^{\prime}$ control & $2^{\prime}$ high $\mathrm{K}^{+}$ \\
\hline Spine synapses & & \\
$\quad$ Spine-PSD & $4.18 \pm 0.81(18)$ & $7.78 \pm 1.37(19)(p<0.05)$ \\
$\quad$ Spine-extrasynaptic & $3.49 \pm 0.58$ & $5.88 \pm 0.66(p<0.05)$ \\
Shaft synapses: PSD & $5.16 \pm 0.57(28)$ & $8.69 \pm 0.60(45)(p<0.0001)$ \\
PSD diameter-spine $(\mu \mathrm{m})$ & $0.302 \pm 0.043$ & $0.284 \pm 0.024$ \\
PSD diameter-shaft $(\mu \mathrm{m})$ & $0.430 \pm 0.043$ & $0.449 \pm 0.021$ \\
\hline
\end{tabular}

Values are given as the mean no. of labels $/ \mu \mathrm{m}$ membrane \pm SEM $(n)$, unless otherwise indicated.

branes, forming a synaptic gap; and (3) clusters of synaptic vesicles in the presynaptic terminals.

Serial sections. Selected areas from series of 12-20 sections (70-80 nm thick) were photographed with a CCD digital camera system (XR-100, AMT) at $10,000 \times$ and printed at a final magnification of $75,000 \times$ for analysis. Serial sectioned spine heads were reconstructed and rendered in Reconstruct (http://synapses.clm.utexas.edu/tools/reconstruct/reconstruct. $\mathrm{stm})$. Differentiation of spine from dendritic shaft synapses was only done in serial section analysis because spines can be confused with small dendrites in single sections (supplemental Fig. $2 \mathrm{~A}$, available at www.jneurosci.org as supplemental material). In single sections, it proved helpful to find a spine neck to identify a synaptic spine (see Fig. $1 C$, large arrow; supplemental Fig. $2 B$, available at www.jneurosci.org as supplemental material)

PSD labeling. A set of criteria was applied to recognizing and counting labels at PSDs. For serial section analyses, the length of the PSDs and the numbers of labels for GluR2 were recorded for each section. The numbers of labels were then pooled and divided by the pooled length of PSDs, and results were expressed as the number of labels per micrometer of PSD length (see examples in supplemental Fig. $2 \mathrm{~A}$, available at www. jneurosci.org as supplemental material). For single sections, every crosssectioned PSD encountered was photographed for measurement, and GluR2 labeling at PSDs was counted as the number of labels per PSD (see examples in supplemental Fig. $2 B$, available at www.jneurosci.org as supplemental material) without normalizing for PSD length. PSD length was not recorded for measurements of single sections because the serial section analysis demonstrated that the mean diameter of PSDs does not change between control and high $\mathrm{K}^{+}$-treated samples (Table 1). In addition, the density of labels for GluR2 showed a consistent trend to increase after depolarization, regardless of whether a label is normalized to PSD length. Not measuring the length of every PSD permitted collecting a very large number of data points, so $>2450$ individual synapses were measured for PSD labeling. Spine membranes lying outside of the PSD areas were also measured and counted for labeling density.

PSD diameter. The longer elliptical axis of serially sectioned PSDs was taken to represent the diameter of the PSD. PSD diameters of spine and shaft synapses were categorized separately in serial sections where their identity can be established unequivocally. All spine synapses are from glutamatergic neurons as GABAergic neurons do not form spines, whereas shaft synapses may come from both types of neurons (Craig et al., 1993).

Neuronal soma labeling. Neuronal somas rather than dendrites were measured because dendritic branches are too convoluted to allow simple comparisons between different dendrites with respect to either their distance from their soma or in their order of branching. Furthermore, it is impossible to tell whether different dendrites were originating from the same soma without extensive serial section analysis. In contrast, somas are easy to identify individually and simple to compare under different experimental conditions. Every neuronal soma encountered in single sections was photographed, and the length of plasma membrane was measured, excluding areas covered by synapses or glial processes to avoid potential undercounting of label due to uneven accessibility of immunolabeling reagents. The number of labels for GluR2 was counted and divided by the length of plasma membrane sampled to derive the number of labels per micrometer in the somal plasma membrane. No differentiation was made between glutamatergic (CaMKII-positive) or GABAergic (CaMKII-negative) neurons as both contain AMPA receptors (Craig et 
al., 1993). In our dissociated cultures, CaMKII-negative neurons constituted $\sim 7-15 \%$ of all neuronal somas ( 3 of 43,4 of 47 , and 10 of 69 neuronal somas, in three experiments).

Recycling endosomes. Recycling endosomes consist of aggregates of vesicles/vacuoles typically situated near edges of somas and dendrites (Cooney et al., 2002). In the present study, recycling endosomes are defined as groups of 3-8 loosely aggregated vesicles/vacuoles not connected to Golgi complexes and occupying areas $200-500 \mathrm{~nm}$ in diameter. In one experiment using NMDA treatment, every neuronal soma encountered was photographed, and structures resembling recycling endosomes within $750 \mathrm{~nm}$ of the plasma membrane were counted. Only labels inside the vesicular lumen were counted as a GluR2 signal. Vesicle aggregates manifesting three or more labels are scored as GluR2-labeled recycling endosomes.

Coated pits. Clathrin-coated pits and vesicles have distinctive features (Petralia et al., 2003). In the present study, coated pits, but not coated vesicles, were scored for labeling for GluR2. Coated vesicles were not counted to rule out the possibility that immunolabeling reagents may not adequately penetrate both plasma membrane and coated vesicle membrane to reach the GluR2 epitopes in the lumen of coated vesicles.

To calculate the percentage of pits labeled with different antibodies, every coated pit on somal and dendritic plasma membranes was counted in micrographs of control samples. In four experiments with NMDA treatment, and in three experiments with glycine treatment, every GluR2-labeled coated pit on somal plasma membrane, as well as the number of GluR2 labels in each coated pit, was counted.

One category of coated pits near synapses was scored separately from the coated pits in somas and dendrites. This category included the following: coated pits in the peri-PSD zone (within $200 \mathrm{~nm}$ of the edge of PSD) of all synapses; and coated pits anywhere along the spine membrane, when spines are identified. This category of coated pits was selected to evaluate the previously described endocytic zones (EZs) (Blanpied et al., 2002; Rácz et al., 2004; Lu et al., 2007; Petrini et al., 2009).

Statistical analysis (KaleidaGraph, Synergy Software) was performed by Student's $t$ test (unmatched sets, unequal variances, or paired $t$ tests, as appropriate) or ANOVA (Tukey test) to test groups of three. Values are expressed as the mean \pm SEM, except in Figure 3, where error bars depict SD.

\section{Results}

Distribution of surface GluR2 label on hippocampal neurons at rest

The GluR2 antibody used here recognizes the N-terminal extracellular domain of the receptor. As expected, neuronal plasma membranes were prominently labeled on the external surfaces of somas (Fig. $1 A, B$ ), dendrites, and spines (Fig. 1C), but label was absent on axons (supplemental Fig. $1 A$, available at www. jneurosci.org as supplemental material). The density of the label for GluR2 varied widely from cell to cell (Fig. $1 A, B$ ) but appeared to be nearly uniform within each cell. For example, a soma with low-density label always gives rise to primary dendrites with similarly low-density label, while a high-density label in a dendrite remains high throughout the traceable distances (Fig. 1C; supplemental Fig. 3, available at www.jneurosci.org as supplemental material). The density of the label also varied widely from synapse to synapse (Fig. 1D-G). GluR2 labeling at PSDs often stood out in dendrites where the density of the label on the plasma membrane was low (supplemental Fig. 3C, available at www.jneurosci. org as supplemental material).

\section{Serial thin section analyses of GluR2 label under control and depolarizing conditions \\ Spine synapses}

An advantage of serial section analysis is that spine heads can be differentiated unequivocally from shaft synapses (supplemental Fig. $2 A$, available at www.jneurosci.org as supplemen-

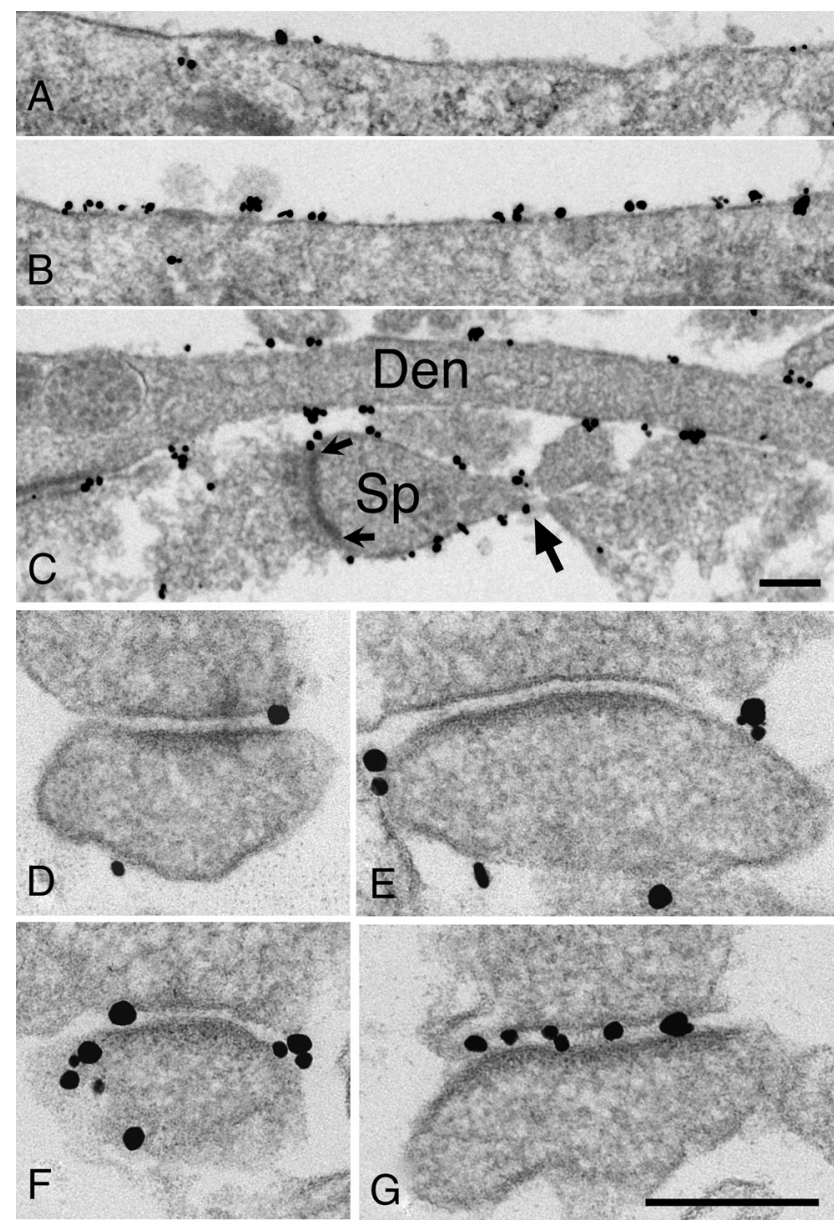

Figure 1. GluR2 labeling of somal, dendritic, and spine membranes. $\boldsymbol{A}, \boldsymbol{B}$, Labeled surfaces of neuronal somas varied from low labeling density $(\boldsymbol{A})$ to high labeling density $(\boldsymbol{B})$. $\boldsymbol{C}$, Uniform distribution of label on surface of a dendrite (Den). One spine (Sp) with a visible neck (large arrow) is labeled over the entire extrasynaptic spine membrane, but the PSD (area between two arrows) is not. $D-G$, Four spine-shaped structures from single sections. The density of label for GluR2 at PSDs ranges from zero $(\boldsymbol{E})$ to low $(\boldsymbol{F})$ to high $(\boldsymbol{G})$. Labeling on the extrasynaptic membranes is also variable; low in $\boldsymbol{D}$ and $\boldsymbol{G}$, and higher in $\boldsymbol{E}$ and $\boldsymbol{F}$. Scale bars: $\boldsymbol{C}$ (for $\boldsymbol{A}-\boldsymbol{C}), \boldsymbol{G}$ (for $\boldsymbol{D}-\boldsymbol{G}$ ), $0.2 \mu \mathrm{m}$.

tal material) (Boyer et al., 1998). Serial reconstructions (Fig. 2; supplemental Fig. 4, available at www.jneurosci.org as supplemental material) provided comprehensive measurements of GluR2 labeling in whole spines (Table 1). Depolarization in high $\mathrm{K}^{+}$produced the most consistent synaptic response (Dosemeci et al., 2001; Tao-Cheng, 2006) among three activation protocols. Thus, we chose to use serial section analysis to document redistribution of GluR2 labeling by comparing sister cultures before and after high $\mathrm{K}^{+}$depolarization. After depolarization, the label for GluR2 significantly increased at spine PSDs ( $186 \%$ of control values, $p<0.05$ ) (Table 1, Fig. 2) as well as in the extrasynaptic spine membrane (168\% of control values, $p<0.05$ ) (Table 1, Fig. 2).

\section{Shaft synapses}

While excitatory synapses on dendritic shafts are rare in the hippocampus of intact brains (Harris et al., 1992; Boyer et al., 1998; Desmond and Weinberg, 1998), they are much more prevalent in dissociated hippocampal cultures, about equal in frequency to spine synapses (Boyer et al., 1998), or outnumber spine synapses by a ratio of 1.85 (Neuhoff et al., 1999). In the two samples ana- 


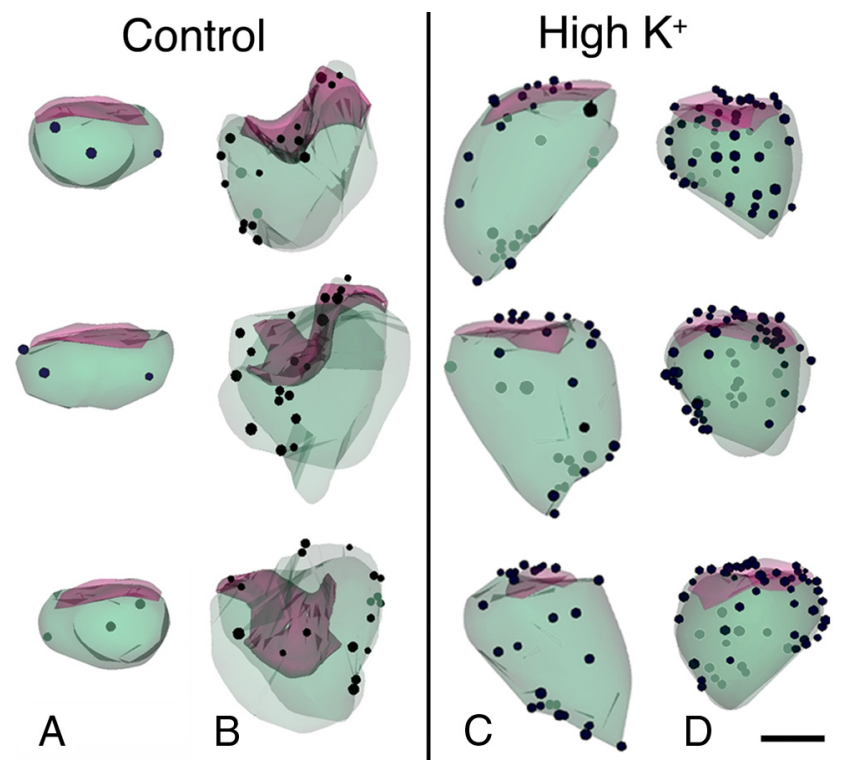

Figure 2. GluR2-labeled spines reconstructed from serial thin sections. $A, B$, Controls. $C$, $D$, Stimulated. Each of the four spines is shown in three different, approximately orthogonal, projections. PSDs are red, extrasynaptic spine membranes are green, and silverenhanced gold labels for GluR2 are shown as black spots (lighter spots lie on the far side of spine). Individual sections from which a control spine $(\boldsymbol{B})$ and a stimulated spine $(\boldsymbol{C})$ were reconstructed are shown in supplemental Figure 3 (available at www.jneurosci.org as supplemental material). Scale bar, $0.2 \mu \mathrm{m}$. lyzed here by serial sections study, shaft synapses outnumber spine synapses by ratios of 1.5 and 2.3, respectively. Dendritic shaft PSDs had a larger diameter than spine PSDs $(p<0.05)$ (Table 1). Upon depolarization, labeling density at shaft PSDs also significantly increased ( $168 \%$ of control values, $p<0.0001$ ) (Table 1).

PSD labeling density versus other plasma membrane domains Under control conditions, the density of GluR2 labeling at spine PSDs did not significantly differ from that at spine extrasynaptic membrane (Table 1$)$ or soma membrane $(2.48 \pm$ 0.27 labels $/ \mu \mathrm{m}, n=36$ ) of the same sample. Furthermore, the labeling density at spine extrasynaptic membrane did not differ significantly from that at soma membrane. Given the small size of the spine sample, we are limited to concluding that any differences in density between spine and somal membranes must be small. Interestingly, labeling density at shaft PSDs was significantly higher than that at either the extrasynaptic membrane of spines $(p<0.05)$ or the soma membrane $(p<$ $0.005)$. After high $\mathrm{K}^{+}$depolarization, the density of the label at PSDs (spine and shaft combined) was greater than that in the rest of the plasma membrane, paralleling the difference in control samples. These results account for the observation that GluR2 labeling at the PSD frequently stands out against the rest of the plasma membrane (supplemental Figs. 2, 3C, available at www.jneurosci.org as supplemental material).

Table 2. Number of GluR2 labels on PSDs from single sections

\begin{tabular}{|c|c|c|c|c|c|c|}
\hline & \multicolumn{6}{|c|}{ Individual experiments } \\
\hline & 2 min control & 2 min high $\mathrm{K}^{+}$ & $\begin{array}{l}2 \min \text { high } \mathrm{K}^{+}+30 \min \\
\text { recovery }\end{array}$ & $2-5$ min control & 3 min glycine & $2-5$ min NMDA \\
\hline & $1.85 \pm 0.23(52)$ & $3.28 \pm 0.44(29) ; p<0.01$ & & $3.01 \pm 0.17(151)$ & $4.51 \pm 0.28(105) ; p<0.0001$ & \\
\hline & $2.07 \pm 0.34(44)$ & $3.33 \pm 0.47(40) ; p<0.05$ & & $4.48 \pm 0.39(42)$ & $6.15 \pm 0.29(118) ; p<0.001$ & $4.84 \pm 0.21(115)$ \\
\hline & $0.83 \pm 0.16(47)$ & $3.37 \pm 0.47(43) ; p<0.0001$ & & $3.36 \pm 0.18(133)$ & $4.26 \pm 0.23(97) ; p<0.005$ & $4.77 \pm 3.53(35) ; p<0.0005$ \\
\hline & $1.67 \pm 0.19(98)$ & $3.71 \pm 0.35(55) ; p<0.0001$ & & $5.46 \pm 1.51(46)$ & & $4.57 \pm 0.32(84)$ \\
\hline & $2.19 \pm 0.37(52)$ & $3.91 \pm 0.32(82) ; p<0.001$ & $1.68 \pm 0.28(50) ; p<0.0001$ & $4.11 \pm 0.25(93)$ & & $4.02 \pm 0.32(62)$ \\
\hline & $1.48 \pm 0.14(179)$ & $4.2 \pm 0.47(42) ; p<0.0001$ & $2.07 \pm 0.21(98) ; p<0.001$ & & & \\
\hline & $2.07 \pm 0.25(71)$ & $3.47 \pm 0.32(68) ; p<0.001$ & $1.64 \pm 0.20(89) ; p<0.0001$ & & & \\
\hline & $1.76 \pm 0.19(93)$ & $4.10 \pm 0.55(31) ; p<0.0005$ & $1.75 \pm 0.20(75) ; p<0.0001$ & & & \\
\hline $\begin{array}{l}\text { Control } / \mathrm{K}^{+} \\
\quad \text { (paired } t \text { test) }\end{array}$ & $1.74 \pm 0.15$ & $3.67 \pm 0.13 ; p<0.0001$ & & & & \\
\hline $\begin{array}{l}\mathrm{K}^{+} / \text {recovery } \\
\quad \text { (paired } t \text { test) }\end{array}$ & & $3.92 \pm 0.32$ & $1.79 \pm 0.1 ; p<0.0005$ & & & \\
\hline
\end{tabular}

Values are given as mean no. of labels/PSD \pm SEM (n).

Table 3. Density of GluR2 label on somal plasma membrane from single sections

\begin{tabular}{|c|c|c|c|c|c|c|}
\hline & \multicolumn{6}{|c|}{ Individual experiments } \\
\hline & 2 min control & 2 min high $\mathrm{K}^{+}$ & $\begin{array}{l}2 \min \text { high } \mathrm{K}^{+}+30 \mathrm{~min} \\
\text { recovery }\end{array}$ & $2-5$ min control & 3 min glycine & $2-5$ min NMDA \\
\hline & $2.48 \pm 0.27(36)$ & $3.87 \pm 0.34(36) ; p<0.005$ & & $1.59 \pm 0.32(25)$ & $1.15 \pm 0.17(36)$ & \\
\hline & $2.01 \pm 0.30(29)$ & $3.10 \pm 0.27(44) ; p<0.01$ & & $1.16 \pm 0.13(55)$ & $1.00 \pm 0.14(46)$ & $1.00 \pm 0.12(33)$ \\
\hline & $2.36 \pm 0.28(19)$ & $4.16 \pm 0.69(16) ; p<0.05$ & & $1.61 \pm 0.21(31)$ & $1.19 \pm 0.21(22)$ & $0.72 \pm 0.15(23) ; p<0.005$ \\
\hline & $1.37 \pm 0.20(35)$ & $3.35 \pm 0.34(17) ; p<0.0001$ & & $1.46 \pm 0.18(28)$ & & $1.12 \pm 0.18(29)$ \\
\hline & $2.31 \pm 0.31(19)$ & $5.04 \pm 1.05(22) ; p<0.05$ & $2.30 \pm 0.39(22) ; p<0.05$ & $1.35 \pm 0.36(23)$ & & $1.36 \pm 0.21(42)$ \\
\hline & $2.04 \pm 0.21(42)$ & $4.66 \pm 0.54(41) ; p<0.0001$ & $1.93 \pm 0.25(46) ; p<0.0001$ & & & \\
\hline & $1.94 \pm 0.28(25)$ & $4.39 \pm 0.38(45) ; p<0.0001$ & $1.98 \pm 0.23(26) ; p<0.0001$ & & & \\
\hline & $2.02 \pm 0.30(22)$ & $2.96 \pm 0.45(27) ; p ; \sim 0.09$ & $1.74 \pm 0.32(28) ; p<0.05$ & & & \\
\hline $\begin{array}{l}\text { Control/ } \mathrm{K}^{+} \\
\quad \text { (paired } t \text { test) }\end{array}$ & $2.07 \pm 0.12$ & $3.94 \pm 0.27 ; p<0.0005$ & & & & \\
\hline $\begin{array}{l}\mathrm{K}^{+} / \text {recovery } \\
\quad \text { (paired } t \text { test) }\end{array}$ & & $4.26 \pm 0.91$ & $1.99 \pm 0.12 ; p<0.01$ & & & \\
\hline
\end{tabular}


Single section analyses of GluR2 labeling under control and depolarizing conditions

Analyses of single sections, which permitted extensive sampling of PSD and somas (see Materials and Methods), confirmed the redistribution of GluR2 labeling upon depolarization, as documented by serial section analysis. Upon high $\mathrm{K}^{+}$depolarization, GluR2 labeling evaluated in single sections significantly increased at the PSD and somal plasma membranes, but returned to basal levels after incubating $30 \mathrm{~min}$ in normal Ringer's solution. This pattern of redistribution was consistent in eight depolarization experiments, including four experiments in which recovery conditions followed depolarization (Tables 2, 3).

Pooled data from all experiments showed $1.74 \pm 0.15$ GluR2 labels per PSD in controls, $3.67 \pm 0.13$ upon high $\mathrm{K}^{+}$, and $1.79 \pm$ 0.10 after 30 min recovery (Fig. 3, left). The mean numbers of labels per PSD after high $\mathrm{K}^{+}$increased to $229 \pm 29 \%$ over control values (paired data from each experiment; Table 2), but returned to $99 \pm 15 \%$ of control after 30 min recovery. Additionally, only $14.3 \pm 1.3 \%$ of PSDs lacked GluR2 labels after high $\mathrm{K}^{+}$, while $36.1 \pm 3.4 \%$ lacked labels in controls, and $35.3 \pm 2.3 \%$ lacked labels after recovery (data not shown). An example of a cumulative frequency plot of a typical experiment is shown in supplemental Figure 5A (available at www.jneurosci.org as supplemental material).

Pooled data from all experiments showed a density of label for GluR2 at somal plasma membranes of $2.07 \pm 0.12$ labels $/ \mu \mathrm{m}$ in the control, $3.94 \pm 0.27$ labels $/ \mu \mathrm{m}$ upon high $\mathrm{K}^{+}$treatment, and $1.99 \pm 0.12$ labels $/ \mu \mathrm{m}$ after $30 \mathrm{~min}$ recovery (Fig. 3 , right). The mean density of label after high $\mathrm{K}^{+}$increased to $194 \pm 14 \%$ of control values (paired $t$ test) (Table 3 ), and after recovery returned to $96 \pm 4 \%$ of control values. An example of a cumulative frequency plot of a typical experiment is shown in supplemental Figure $5 B$ (available at www. jneurosci.org as supplemental material).

These results validated the use of single section analysis for detecting changes of GluR2 labeling at the PSD and somal membranes, and we proceeded to document GluR2 redistribution under other activation conditions that are known to induce exocytosis and endocytosis of AMPA receptors, respectively.

\section{Redistribution of GluR2 labeling after synaptic stimulation}

We used a chemical stimulation protocol similar to $\mathrm{Lu}$ et al. (2001), with $200 \mu \mathrm{M}$ glycine $/ 0 \mathrm{Mg}^{2+} / 1 \mu \mathrm{M}$ strychnine to induce synaptic activation. After $3 \mathrm{~min}$ of treatment, GluR2 labeling at PSD significantly increased to $138 \pm 7 \%$ of control levels (three experiments) (Table 2, paired $t$ test). However, unlike high $\mathrm{K}^{+}$ depolarization, labeling of somal plasma membrane did not increase significantly (Table 3).

\section{Evidence for exocytosis of AMPA receptors}

Chemical stimulation protocols similar to that used here (Lu et al., 2001) have been used to capture increased exocytosis by

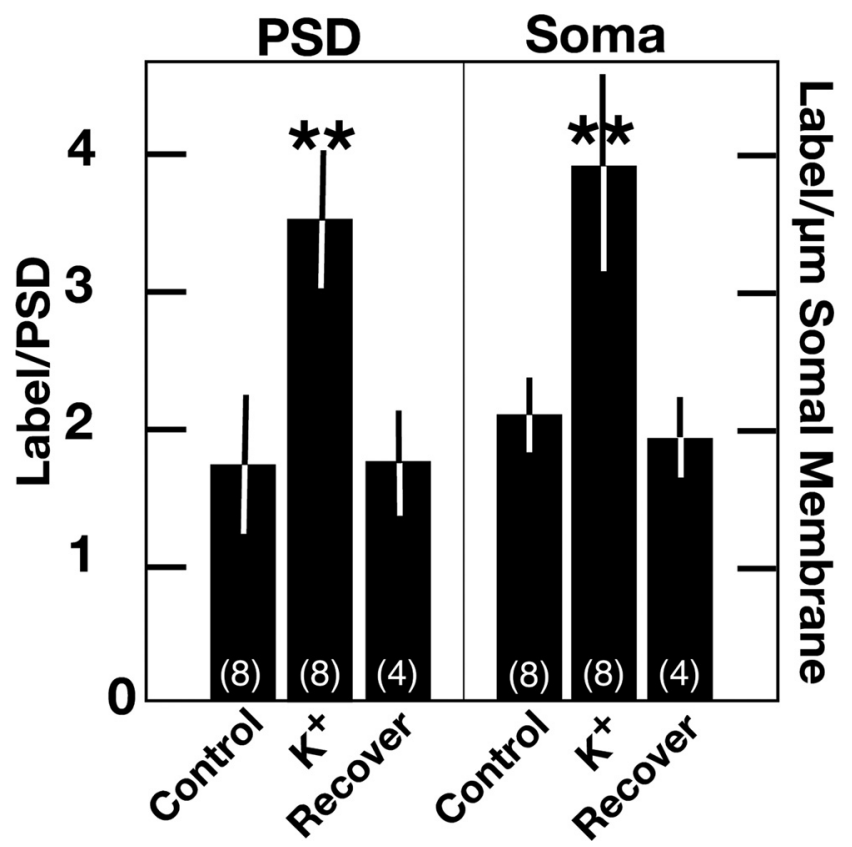

Figure 3. Label for GluR2 at PSDs and somas after depolarization with high $\mathrm{K}^{+}$. PSDs and somal membranes show significant increases in label for GluR2 after high $\mathrm{K}^{+}$treatment $(90 \mathrm{~mm}$ for $2 \mathrm{~min}$ ), and a return to control levels upon return to normal medium for $30 \mathrm{~min}$ (Recover). Error bars represent SDs. Number of experiments is shown at bottom of bars. Data from each experiment are detailed in Tables 2 and $3 .{ }^{*}$ indicate difference from control is significant $(p<0.0005)$

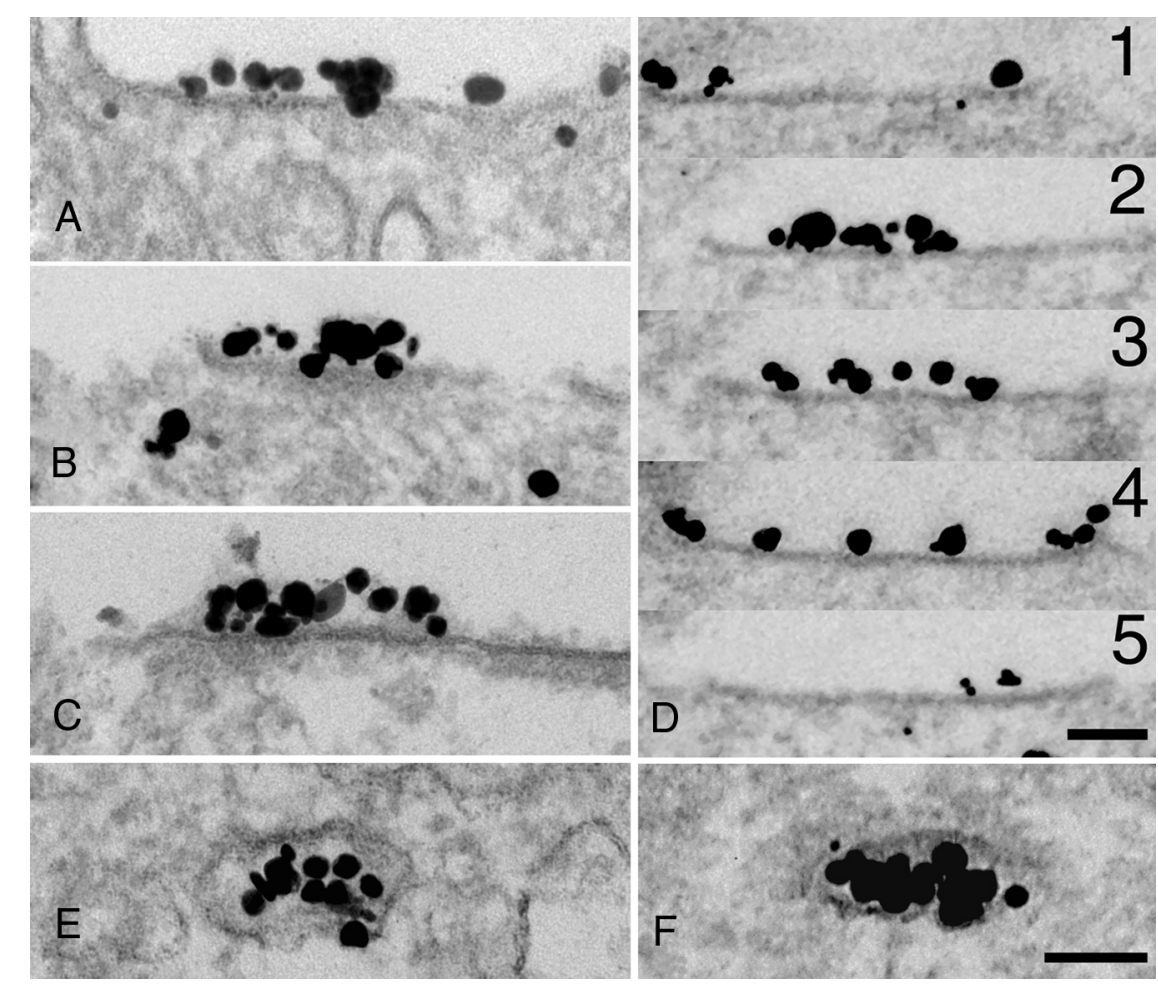

Figure 4. Evidence for exocytosis of AMPA receptors at neuronal plasmalemmas. $A-C$, Patches of concentrated label for GluR2, which may represent aftermath of recent exocytic events, are seen at low frequency in control samples $(\boldsymbol{A})$ and at higher frequencies in high $\mathrm{K}^{+}$depolarized samples $(\boldsymbol{B}, \boldsymbol{C}$ ). Serial sections in $\boldsymbol{D}$ (sections $1-5$ ) show that the label is more concentrated at the cente of the patch (sections 2 and 3). Number of labels counted are 10,9, and 11 in sections 2, 3, and 4, respectively. $\boldsymbol{E}, \boldsymbol{F}$, GluR2-labeled vacuoles containing concentrated labels occasionally lie near edges of a soma $\left(\boldsymbol{E}\right.$, NMDA-treated) or a dendrite $\left(\boldsymbol{F}, 2 \mathrm{~min} \mathrm{~K}^{+}\right.$ followed by $5 \mathrm{~min}$ recovery in Ringer's solution). Scale bars: $\boldsymbol{D}, \boldsymbol{F}$ (for $\boldsymbol{A}-\boldsymbol{C}, \boldsymbol{E}, \boldsymbol{F}), 0.1 \mu \mathrm{m}$. 
Table 4. Patches of plasma membrane labeled for GluR2 under different experimental conditions

\begin{tabular}{llll}
\hline & Control & Glycine & High K $^{+}$ \\
\hline Length $(\mathrm{nm})$ (no. of patches) $^{a}$ & $180 \pm 9(15)$ & $178 \pm 9(17)$ & $192 \pm 6(55)$ \\
Density of label (label $/ \mu \mathrm{m}$ of patch) $^{a}$ & $47.7 \pm 2.3$ & $51.4 \pm 2.5$ & $50.8 \pm 1.3$ \\
Labeled patches per 100 soma profiles $^{b}$ & $2.73 \pm 0.64(14,535)$ & $6.44 \pm 1.10(4,213)$ & $12.90 \pm 1.16(17,397) ; p<0.0001$ vs control (ANOVA) \\
$\quad$ (no. of experiments, no. of somas) & & &
\end{tabular}

(no. of experiments, no. of somas)

Values are given as mean \pm SEM $(n)$.

${ }^{a}$ From somas and dendrites.

${ }^{b}$ Somas only.

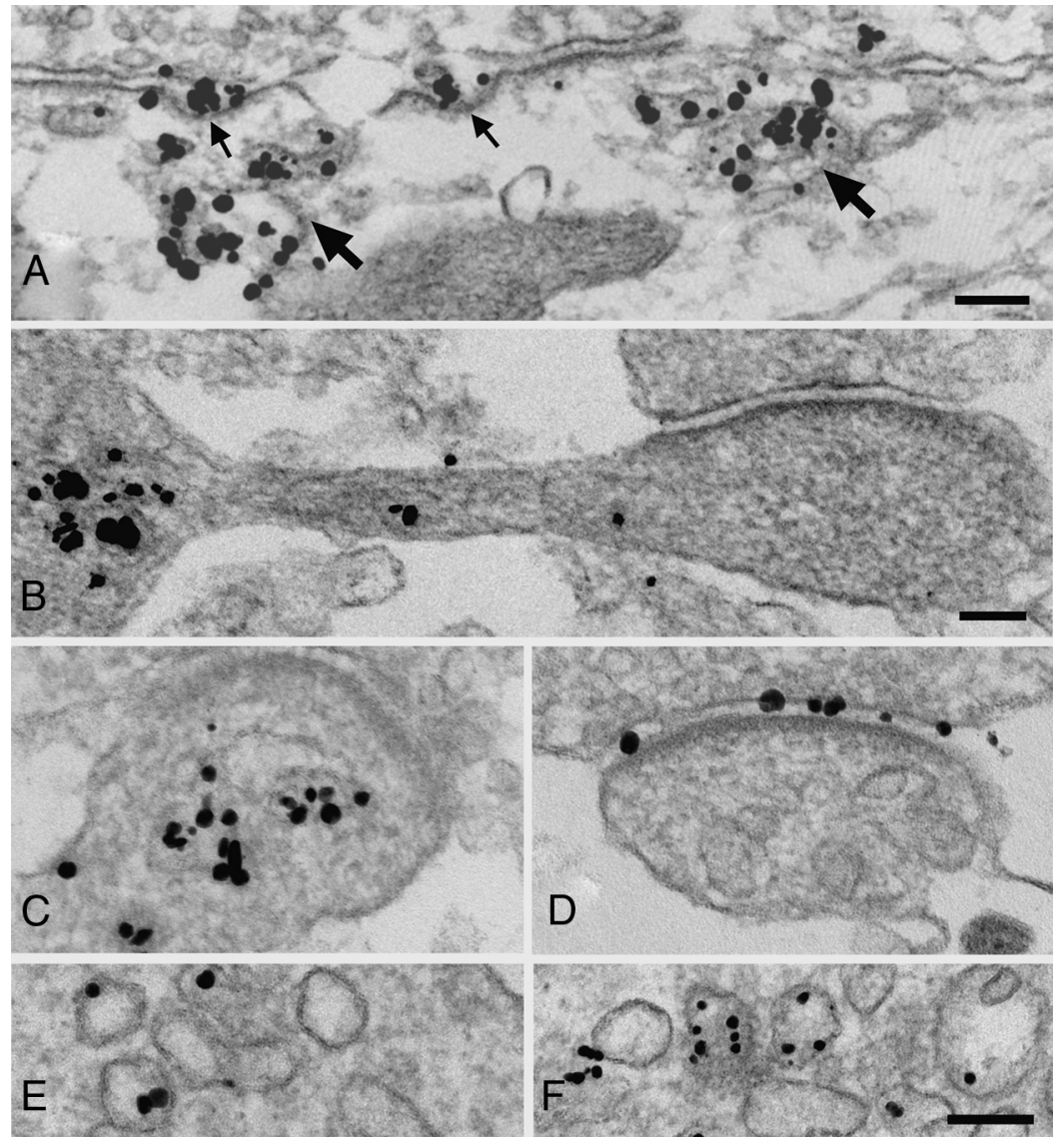

Figure 5. Recycling endosomes label intensely for transferrin receptors $(\boldsymbol{A}-\boldsymbol{C}$ ), but sparsely for GluR2 (D-F). Recycling endosomes consisting of aggregates of tubular/vesicular structures intensely labeled for TfRs (large arrows) are commonly situated near surfaces of dendrites $(\boldsymbol{A})$ or near the base of spines $(\boldsymbol{B})$. $\boldsymbol{A}$, Two small arrows point to TfR-labeled coated pits near synapses at the surface of a dendrite. C, Recycling endosomes consistently label for TfRs and occur in $\sim 35 \%$ of spine-like structures. $\boldsymbol{D}$, However, recycling endosome-like vesicles in spines rarely label for GluR2.E, $\boldsymbol{F}$, Recycling endosomes in dendrites and soma are infrequently labeled with GluR2, and the density of label under control conditions is low $(\boldsymbol{E})$, while both the frequency and density of label increase after NMDA treatment $(\boldsymbol{F})$. Scale bar, $0.1 \mu \mathrm{m}$.

light microscopy (Yudowski et al., 2007; Makino and Malinow, 2009; Kennedy et al., 2010). Corresponding evidence of exocytosis from electron microscopy could consist of vesicles or vacuoles near the plasma membrane with GluR2 labels on their luminal sides, but no such evidence was readily apparent. However, patches of highly concentrated GluR2 label on the plasma membranes of soma occurred at very low frequency in control samples (Fig. 4A) or at slightly higher frequency, though just short of statistical significance, in Gly/0 $\mathrm{Mg}^{2+}$ samples (Table 4; supplemental Fig. 6, available at www.jneurosci.org as supplemental material). These patches had a labeling density much higher than anywhere else on the neuronal surface. Although rare, these patches warranted a closer examination because the consistency in their size and labeling density (Table 4) suggested a uniform set of events, possibly representing exocytosis of the GluR2 from a single vesicle.

After high $\mathrm{K}^{+}$depolarization, patches of concentrated GluR2 label became significantly more frequent (Fig. $4 B, C$, Table 4). In an example from serial sections (Fig. $4 D$ ), patches were apparent in three adjacent sections, showing $\sim 30$ labels in a patch $\sim 0.3 \mu \mathrm{m}$ in diameter, yet only the middle sections (2 and 3 ) would have been identified as a GluR2 patch in single sections. The size and density of GluR2 label in these patches are virtually identical with those seen in control and Gly/0 $\mathrm{Mg}^{2+}$ samples, but occurred at different frequencies (Table 4). These observations together suggest that the patches represent a unitary event, most likely a single exocytosis inserting AMPA receptors into the cell surface.

The patches of GluR2 label did not contain dense material underneath the plasma membrane, which characterizes PSDs, and they are unlikely to represent clumping of secondary antibodies because clumps typically include only two to six grains and do not flatten out against the plasma membrane. GluR2-labeled patches were limited to somas and dendrites, and none were near PSDs. Due to their low frequency and the limitations in sampling inherent to electron microscopy of thin sections, patches near PSDs could escape detection, but with $>3000$ PSDs examined here it is necessary to conclude that patches of AMPA receptors are uncommon near PSDs under our experimental conditions.

If patches represent the aftermath of exocytosis of a vesicle containing AMPA receptors, vesicles with concentrated GluR2 labels should be arrayed near the plasma membrane. A few labeled vesicles with dimensions close to those of the labeled patches occurred near somal (Fig. 4E) or dendritic (Fig. 4F) plasma membranes.

\section{Recycling endosomes}

Identification of recycling endosomes by immunolabeling of transferrin receptors

Recycling endosomes are involved in AMPA receptor exocytosis (Ehlers, 2000; Park et al., 2004, 2006; Lu et al., 2007; Jaskolski et al., 2009; Kennedy et al., 2010) and would be expected to label for 
GluR2. TfR is a marker for recycling endosomes (Dautry-Varsat, 1986; Maxfield and McGraw, 2004), so immunogold labeling of TfR was used to identify recycling endosomes here. ER in neuronal somas and dendrites did not label with TfR antibody (supplemental Fig. 7, available at www.jneurosci.org as supplemental material), distinguishing it from recycling endosomes. As expected, all structures resembling recycling endosomes (Cooney et al., 2002) labeled intensely for TfR. The TfR-labeled aggregates of tubular/vesicular structures were located mainly in dendritic shafts (Fig. $5 A$ ) and near surfaces edges of neuronal somas (supplemental Fig. 7, available at www.jneurosci.org as supplemental material). Where fortuitous sections showed the connection of a spine with the dendritic shaft, a TfR-labeled recycling endosome was located in the shaft at the base of the spine, with a few TfR labels in the neck, and no labels in the spine head (Fig. $5 B$ ). Of all spine-like structures, 35\% (18 of 51) contained TfR-labeled vesicles/vacuoles (Fig. 5C). The distribution of the bulk of the TfR labeling in soma/dendrites, with some in spines is consistent with that of recycling endosomes (Cooney et al., 2002; Park et al., 2004, 2006).

\section{GluR2 labeling of recycling endosomes}

In contrast with the consistent and intense labeling of TfR in recycling endosomes in dendrites and somas, structures resembling recycling endosomes labeled for GluR2 at a lower frequency and intensity. Under control conditions, some labels marked lumens of a few of the tubular/vesicular structures (Fig. 5E). After 2-5 min of NMDA treatment, which is known to induce endocytosis of AMPA receptors (Ehlers, 2000; Ashby et al., 2004; Lin and Huganir, 2007), structures resembling recycling endosomes labeled with GluR2 at higher frequencies, and these vesicles collectively had more label (Fig. $5 F$ ) than under control conditions (Fig. $5 E$ ). For example, in one experiment where measurements were made in neuronal somas (see Materials and Methods), the percentages of structures resembling recycling endosomes labeled for GluR2 were 28\% $(n=42)$ and $47 \%(n=34)$, respectively, under control and NMDA treatment conditions. The number of labels in these labeled structures increased from $4.6 \pm 0.4$ in the control sample to $7.9 \pm 0.6(p<0.0001)$ in the NMDA-treated sample. These results indicate that some AMPA receptors reside in recycling endosomes under basal conditions, and more are induced after enhancing endocytosis with NMDA treatment (Fig. $5 F$ ). These GluR2-labeled, putative recycling endosomes were near the edges of somas and in dendritic shafts, but no credible GluR2 labeling was detected in vesicles that resemble recycling endosome in spine-like structures (Fig. 5D). This paucity of intracellular AMPA receptor labeling in spines is consistent with immunolabeling by light (Ashby et al., 2006; Jaskolski et al., 2009) and electron microscopy (Lee et al., 2001; Petralia et al., 2003).

\section{Endocytosis of AMPA receptors}

Endocytosis at cell bodies and dendrites

AMPA receptors are internalized through clathrin-mediated endocytosis (Carroll et al., 1999; Man et al., 2000), but it is possible that not all endocytosis events involve AMPA receptors. Virtually all $(98 \%)$ coated pits and vesicles near the plasma membrane of neuronal somas and their dendrites were labeled by an antibody to clathrin ( $n=89$, six samples) (Fig. $6 C$, top). However, only $\sim 20 \%$ of the coated pits in somal and dendritic plasma membranes ( $n=152$, four samples under basal conditions) (Fig. $6 \mathrm{~A}$, top) labeled for GluR2. We also compared a pair of parallel cultures labeled separately for TfR (Fig. 6D, top) or for GluR2. The majority $(75.5 \%)$ of coated pits on somal plasma membrane labeled for TfR, while only $23.7 \%$ labeled for GluR2.

NMDA $(20-30 \mu \mathrm{M})$ (see Materials and Methods) was applied for 2-5 min to induce endocytosis of AMPA receptors. The frequency of GluR2-labeled pits (labeled pits/100 soma profiles) increased significantly to $227 \pm 37 \%$ of control value (paired $t$ test, $p<0.05$ ) (Table 5), while the frequency of unlabeled pits did not change (Table 5). Additionally, the number of labels per labeled pit increased significantly to $178 \pm 20 \%$ of control value (paired $t$ test, $p<0.05$ ) (Table 5; Fig. $6 B$, top). Thus, after NMDA treatment, the total number of GluR2-labeled pits in neuronal somas approximately doubled, and individual pits contained more label. The combined effect of the increases in number of labeled pits and label per pit would reflect a $\sim 400 \%$ increase in 
Table 5. GluR2 labeling of coated pits in somal plasma membranes

\begin{tabular}{|c|c|c|c|c|c|c|c|c|c|}
\hline & \multicolumn{3}{|c|}{ Labeled pits per 100 somal profiles (no. of somas) } & \multicolumn{3}{|c|}{ Unlabeled pits per 100 somal profiles } & \multicolumn{3}{|c|}{ Grains per labeled pit (no. of labeled pits) } \\
\hline & Control & NMDA & Glycine & Control & NMDA & Glycine & Control & NMDA & Glycine \\
\hline & $32.3(31)$ & $71.0(31)$ & & 135.5 & 122.6 & & $1.1(10)$ & $2.45(22)$ & \\
\hline & $15.4(26)$ & $50.0(26)$ & & 42.3 & 119.2 & & 1.25 (4) & 1.77 (13) & \\
\hline & $16.7(36)$ & $36.0(25)$ & $20.8(48)$ & 69.4 & 80.0 & 52.1 & $1.33(6)$ & $2.67(9)$ & $1.8(10)$ \\
\hline & $14.7(34)$ & $21.4(28)$ & $25.9(53)$ & 144.1 & 182.1 & 55.6 & $1.6(5)$ & $2.33(6)$ & 1.71 (14) \\
\hline & $20.7(29)$ & & $50.8(61)$ & 65.5 & & 98.4 & $1.5(6)$ & & 1.81 (18) \\
\hline Control/NMDA (paired $t$ test) & $19.8 \pm 4.2^{a}$ & $44.6 \pm 10.6(p<0.05)$ & & $97.8 \pm 24.9$ & $126 \pm 21.1$ & & $1.32 \pm 0.10$ & $2.31 \pm 0.19(p<0.05)$ & \\
\hline Control/glycine (paired $t$ test) & $17.4 \pm 1.8$ & & $32.5 \pm 9.3$ & $93.0 \pm 25.6$ & & $68.7 \pm 14.9$ & $1.48 \pm 0.08$ & & $1.77 \pm 0.03$ \\
\hline
\end{tabular}

${ }^{a}$ Values are given as mean \pm SEM.

AMPA receptor internalization. Endocytosis of AMPA receptors was also assessed in glycine-treated samples. Although the frequency of GluR2-labeled pits and the number of GluR2 labels per labeled pit both appeared to increase after glycine treatment, increases fell short of statistical significance.

\section{Endocytosis near synapses}

Clathrin-coated pits can lie lateral to PSDs, either immediately next to PSD (peri-PSD) or on the extrasynaptic spine membrane. Such pits have been designated to belong to an endocytic zone (EZ) (Blanpied et al., 2002, Rácz et al., 2004), but EZs did not label for AMPA receptors by EM immunogold labeling (Petralia et al., 2003). In the present study, coated pits in what would be EZs are not frequent, a finding consistent with serial thin section analysis of adult hippocampus (Cooney et al., 2002). Here, a total of 33 peri-PSD coated pits occurred at 1300 synaptic profiles in control samples, and 31 of these did not label for GluR2 (Fig. 6A, bottom). The few GluR2-labeled peri-PSD pits we did find indicate that endocytosis of GluR2 can occur near synapses, but that in total it must involve a very small fraction of the AMPA receptors being endocytosed in the neuron, because they are much less frequent than those in somal and dendritic membranes. Furthermore, coated pits occur at the edges of both inhibitory (Fig. $6 C$, bottom) and excitatory synapses (Fig. $6 A$, bottom, $B$, bottom), suggesting that peri-PSD endocytosis does not necessarily involve endocytosis of AMPA receptors.

After NMDA treatment, there is an increase in the number of peri-PSD pits, and more of these pits labeled for GluR2 (Fig. $6 \mathrm{~B}$, bottom). Of 24 peri-PSD coated pits in 520 synaptic profiles from NMDA-treated samples, 10 contained GluR2 label. Compared with control samples, their frequency increased from $\sim 25$ to 46 peri-PSD pits per 1000 synaptic profiles, and the percentage of GluR2-labeled peri-PSD pits increased from 6 to $42 \%$ in NMDAtreated samples. Thus, internalization of AMPA receptors can occur at locations immediately lateral to PSD, especially after NMDA treatment. In contrast, when peri-PSD coated pits were examined for TfR labeling, 93\% (14 of 15) labeled for TfR (Fig. $6 D$, bottom).

Despite this NMDA-induced increase of endocytosis of AMPA receptors at peri-PSD locations, GluR2 labeling density at the PSDs did not change significantly after NMDA treatment (108 $\pm 12 \%$ of control values, four experiments) (Table 2$)$. This finding is consistent with previous light microscopic immunolabeling studies (Ehlers, 2000; Ashby et al., 2004; Lin and Huganir, 2007).

\section{Discussion}

The present study combines sensitive pre-embedding immunogold electron microscopy with serial thin sectioning to demonstrate the distribution of AMPA receptors on the plasma membranes of spines, dendrites, and somas of dissociated hip- pocampal neurons. An antibody to the GluR2 subunit of AMPA receptors thoroughly samples endogenous AMPA receptors, which exist as tetramers of GluR1/2 or GluR2/3 subunits (Wenthold et al., 1996). This antibody readily accesses AMPA receptors on the surface of the plasma membrane in dissociated hippocampal neuronal cultures due to the extracellular location of the GluR2 epitope (Vissavajjhala et al., 1996). Thus, we are able to document, at the level of individual AMPA receptors, their distribution over the entire neuronal surface, under resting, stimulation, and recovery conditions. Determining the distribution of AMPA receptors at this level of detail also provides new evidence for the distribution of exocytosis and endocytosis events.

Label at PSDs often stands out from the rest of the plasma membrane, consistent with previous studies by postembedding immunogold labeling (Kharazia et al., 1996; Bernard et al., 1997; Nusser et al., 1998; Takumi et al., 1999; Ganeshina et al., 2004). However, it is possible that receptors at the PSD are undercounted with the pre-embedding method because the antibody must penetrate the synaptic cleft. On the other hand, preembedding labeling reveals substantial labeling of the plasma membrane outside of synapses, including neuronal somas, dendritic branches, and the spines, representing a vast potential reservoir of AMPA receptors (Groc et al., 2004; Petrini et al., 2009) that can rapidly move in and out of synaptic zones (Borgdorff and Choquet, 2002).

The density of label for GluR2 varies widely from neuron to neuron and from spine to spine, a finding consistent with previous reports on the distribution of AMPA receptors in intact brains (Nusser et al., 1998). Although the serial sectioning here was not extensive enough to reconstruct whole dendritic branches, fragmentary reconstructions and longitudinal sections along dendritic branches indicate that labeling density is essentially uniform over regions 10-20 $\mu \mathrm{m}$ long within the same neuron. This observation is consistent with the idea that the distribution of AMPA receptors is at equilibrium throughout each neuron, except at synapses and in axons (Adesnik et al., 2005; Ashby et al., 2006; Makino and Malinow, 2009).

Synaptic plasticity has been linked to regulation of the number of AMPA receptors at synapses, which, in turn, is determined by the balance between their exocytosis and endocytosis (for review, see Malinow and Malenka, 2002; Shepherd and Huganir, 2007; Santos et al., 2009). Live imaging of superecliptic pHluorin (a $\mathrm{pH}$-sensitive green fluorescent protein variant) tagged GluR has elegantly portrayed locations and frequencies of exocytosis under different conditions (Yudowski et al., 2007; Lin et al., 2009; Jaskolski et al., 2009; Makino and Malinow, 2009; Araki et al., 2010; Kennedy et al., 2010). However, electron microscopy has yet to capture the expected images of vesicles labeled for AMPA receptors fusing with the plasma membrane. The few intensely labeled GluR2-positive vacuoles observed in the present study are diffi- 
cult to reconcile with the large numbers of exocytosis events captured by live light microscopy. Nevertheless, it is likely that we have detected the aftermath of individual exocytic events involving AMPA receptors, appearing as concentrated patches of GluR2 label on somal and dendritic plasma membranes. These patches have relatively a uniform size and number of labels, and occur in different frequencies under different conditions, ranging, as expected, from low under basal conditions to high after high $\mathrm{K}^{+}$ depolarization. Furthermore, in terms of estimated number of receptors per exocytosis event, the concentrated patches (with $\sim 30$ labels from consecutive sections) are in line with what was calculated from the live cell observations ( $\sim 51$ receptors) (Yudowski et al., 2007).

In contrast, electron microscopy provides unmistakable images of clathrin-coated endocytosis of AMPA receptors. In a pair of sister cultures under basal conditions, approximately one quarter of coated pits on somas and dendrites label for GluR2, while three quarters label for TfRs. It is possible that this difference merely reflects a technical difference in labeling efficiency of the two antibodies. Alternatively, these results suggest that not all clathrin-coated pits are involved in AMPA receptor endocytosis, and that TfR may be endocytosed separately from AMPA receptors. We also show that NMDA-induced AMPA receptor endocytosis is achieved through increases in both the number of GluR2-labeled pits and the number of labels in each pit. The indication that glycine treatment might also increase GluR2 endocytosis is not surprising because glycine is an NMDA coactivator (Lu et al., 2001). It is interesting, however, that after glycine treatment, the balance of increased exocytosis and endocytosis yielded a net increase in PSD labeling of AMPA receptors but no increase in label in soma plasma membrane. Possibly, AMPA receptors being added to the surface due to increased exocytosis are quickly captured at the PSD.

Coated pits in the vicinity of the PSD are thought to comprise specialized endocytic zones (EZs) (Blanpied et al., 2002, Rácz et al., 2004), mediating endocytosis of AMPA receptors for local recycling in the spines ( $\mathrm{Lu}$ et al., 2007; Petrini et al., 2009; Kennedy et al., 2010). However, an early examination by postembedding immunogold electron microscopy failed to detect label for AMPA receptors in EZs (Petralia et al., 2003), a finding we confirm in that peri-PSD pits rarely labeled for GluR2 under control conditions. This lack of AMPA receptor labeling under basal conditions is not due to technical limitation of immunolabeling methods, as virtually all such peri-PSD pits labeled for TfR, indicating ample accessibility of reagents at these locations. Furthermore, after NMDA treatment, GluR2 label appeared in a significantly higher percentage of peri-PSD coated pits, demonstrating that these pits are accessible for GluR2 immunolabeling. This latter observation also suggests that peri-PSD endocytosis of AMPA receptors near synapses are highly regulated by activity.

In conclusion, neurons at rest manifest many AMPA receptors throughout the surfaces of their dendrites and cell bodies, and the receptors redistribute upon activity. Plasma membrane patches of concentrated receptor labeling, signatures of the aftermath of exocytosis events, occur at low frequency under basal conditions, and increase progressively after glycine treatment and high $\mathrm{K}^{+}$depolarization. The zone around the PSD holds no special attraction for exocytosis of AMPA receptors, supporting the idea that addition of AMPA receptors to the PSDs comes largely from lateral diffusion. A subpopulation of clathrin-coated pits in somal and dendritic plasma membranes is involved in AMPA receptor endocytosis, and NMDA treatment increases the number of pits labeling for AMPA receptors as well as the amount of label in each pit, resulting in a fourfold increase in internalized receptors. Endocytosis of AMPA receptors near PSDs rarely occurs under basal conditions, but increases significantly after NMDA treatment. While there is no evidence from electron microscopy so far that exocytosis adds AMPA receptors at peri-PSD locations, some endocytosis of AMPA receptors does occur adjacent to PSDs under certain conditions, such as activation of NMDA receptors.

\section{References}

Adesnik H, Nicoll RA, England PM (2005) Photoinactivation of native AMPA receptors reveals their real-time trafficking. Neuron 48:977-985.

Araki Y, Lin DT, Huganir RL (2010) Plasma membrane insertion of the AMPA receptor GluA2 subunit is regulated by NSF binding and Q/R editing of the ion pore. Proc Natl Acad Sci U S A 107:11080-11085.

Ashby MC, De La Rue SA, Ralph GS, Uney J, Collingridge GL, Henley JM (2004) Removal of AMPA receptors (AMPARs) from synapses is preceded by transient endocytosis of extrasynaptic AMPARs. J Neurosci 24:5172-5176.

Ashby MC, Maier SR, Nishimune A, Henley JM (2006) Lateral diffusion drives constitutive exchange of AMPA receptors at dendritic spines and is regulated by spine morphology. J Neurosci 26:7046-7055.

Bassani S, Valnegri P, Beretta F, Passafaro M (2009) The GLUR2 subunit of AMPA receptors: synaptic role. Neuroscience 158:55-61.

Bernard V, Somogyi P, Bolam JP (1997) Cellular, subcellular, and subsynaptic distribution of AMPA-type glutamate receptor subunits in the neostriatum of the rat. J Neurosci 17:819-833.

Blanpied TA, Scott DB, Ehlers MD (2002) Dynamics and regulation of clathrin coats at specialized endocytic zones of dendrites and spines. Neuron 36:435-449.

Borgdorff AJ, Choquet D (2002) Regulation of AMPA receptor lateral movements. Nature 417:649-653.

Boyer C, Schikorski T, Stevens CF (1998) Comparison of hippocampal dendritic spines in culture and in brain. J Neurosci 18:5294-5300.

Carroll RC, Beattie EC, Xia H, Lüscher C, Altschuler Y, Nicoll RA, Malenka RC, von Zastrow M (1999) Dynamin-dependent endocytosis of ionotropic glutamate receptors. Proc Natl Acad Sci U S A 96:14112-14117.

Choquet D (2010) Fast AMPAR trafficking for a high-frequency synaptic transmission. Eur J Neurosci 32:250-260.

Cooney JR, Hurlburt JL, Selig DK, Harris KM, Fiala JC (2002) Endosomal compartments serve multiple hippocampal dendritic spines from a widespread rather than a local store of recycling membrane. J Neurosci 22:2215-2224.

Craig AM, Blackstone CD, Huganir RL, Banker G (1993) The distribution of glutamate receptors in cultured rat hippocampal neurons: postsynaptic clustering of AMPA-selective subunits. Neuron 10:1055-1068.

Dautry-Varsat A (1986) Receptor-mediated endocytosis: the intracellular journey of transferrin and its receptor. Biochimie 68:375-381.

Desmond NL, Weinberg RJ (1998) Enhanced expression of AMPA receptor protein at perforated axospinous synapses. Neuroreport 9:857-860.

Dosemeci A, Tao-Cheng JH, Vinade L, Winters CA, Pozzo-Miller L, Reese TS (2001) Glutamate-induced transient modification of the postsynaptic density. Proc Natl Acad Sci U S A 98:10428-10432.

Ehlers MD (2000) Reinsertion or degradation of AMPA receptors determined by activity-dependent endocytic sorting. Neuron 28:511-525.

Ganeshina O, Berry RW, Petralia RS, Nicholson DA, Geinisman Y (2004) Differences in the expression of AMPA and NMDA receptors between axospinous perforated and nonperforated synapses are related to the configuration and size of postsynaptic densities. J Comp Neurol 468:86-95.

Gerges NZ, Backos DS, Rupasinghe CN, Spaller MR, Esteban JA (2006) Dual role of the exocyst in AMPA receptor targeting and insertion into the postsynaptic membrane. EMBO J 25:1623-1634.

Groc L, Heine M, Cognet L, Brickley K, Stephenson FA, Lounis B, Choquet D (2004) Differential activity-dependent regulation of the lateral mobilities of AMPA and NMDA receptors. Nat Neurosci 7:695-696.

Groc L, Lafourcade M, Heine M, Renner M, Racine V, Sibarita JB, Lounis B, Choquet D, Cognet L (2007) Surface trafficking of neurotransmitter receptor: comparison between single-molecule/quantum dot strategies. J Neurosci 27:12433-12437.

Harris KM, Jensen FE, Tsao B (1992) Three-dimensional structure of dendritic spines and synapses in rat hippocampus (CA1) at postnatal day 15 
and adult ages: implications for the maturation of synaptic physiology and long-term potentiation. J Neurosci 12:2685-2705.

Hirling H (2009) Endosomal trafficking of AMPA-type glutamate receptors. Neuroscience 158:36-44.

Jaskolski F, Henley JM (2009) Synaptic receptor trafficking: the lateral point of view. Neuroscience 158:19-24.

Jaskolski F, Mayo-Martin B, Jane D, Henley JM (2009) Dynamindependent membrane drift recruits AMPA receptors to dendritic spines. J Biol Chem 284:12491-12503.

Kennedy MJ, Davison IG, Robinson CG, Ehlers MD (2010) Syntaxin-4 defines a domain for activity-dependent exocytosis in dendritic spines. Cell 141:524-535.

Kharazia VN, Phend KD, Rustioni A, Weinberg RJ (1996) EM colocalization of AMPA and NMDA receptor subunits at synapses in rat cerebral cortex. Neurosci Lett 210:37-40.

Larsson M, Broman J (2008) Translocation of GluR1-containing AMPA receptors to a spinal nociceptive synapse during acute noxious stimulation. J Neurosci 28:7084-7090.

Lee SH, Valtschanoff JG, Kharazia VN, Weinberg R, Sheng M (2001) Biochemical and morphological characterization of an intracellular membrane compartment containing AMPA receptors. Neuropharmacology 41:680-692.

Lin DT, Huganir RL (2007) PICK1 and phosphorylation of the glutamate receptor 2 (GluR2) AMPA receptor subunit regulates GluR2 recycling after NMDA receptor-induced internalization. J Neurosci 27:13903-13908.

Lin DT, Makino Y, Sharma K, Hayashi T, Neve R, Takamiya K, Huganir RL (2009) Regulation of AMPA receptor extrasynaptic insertion by $4.1 \mathrm{~N}$, phosphorylation and palmitoylation. Nat Neurosci 12:879-887.

Lu J, Helton TD, Blanpied TA, Rácz B, Newpher TM, Weinberg RJ, Ehlers MD (2007) Postsynaptic positioning of endocytic zones and AMPA receptor cycling by physical coupling of dynamin-3 to Homer. Neuron $55: 874-889$.

Lu W, Man H, Ju W, Trimble WS, MacDonald JF, Wang YT (2001) Activation of synaptic NMDA receptors induces membrane insertion of new AMPA receptors and LTP in cultured hippocampal neurons. Neuron 29:243-254.

Makino H, Malinow R (2009) AMPA receptor incorporation into synapses during LTP: the role of lateral movement and exocytosis. Neuron 64:381-390.

Malinow R, Malenka RC (2002) AMPA receptor trafficking and synaptic plasticity. Annu Rev Neurosci 25:103-126.

Man HY, Lin JW, Ju WH, Ahmadian G, Liu L, Becker LE, Sheng M, Wang YT (2000) Regulation of AMPA receptor-mediated synaptic transmission by clathrin-dependent receptor internalization. Neuron 25:649-662.

Masugi-Tokita M, Shigemoto R (2007) High-resolution quantitative visualization of glutamate and GABA receptors at central synapses. Curr Opin Neurobiol 17:387-393.

Maxfield FR, McGraw TE (2004) Endocytic recycling. Nat Rev Mol Cell Biol 5:121-132.
Moga DE, Shapiro ML, Morrison JH (2006) Bidirectional redistribution of AMPA but not NMDA receptors after perforant path simulation in the adult rat hippocampus in vivo. Hippocampus 16:990-1003.

Neuhoff H, Roeper J, Schweizer M (1999) Activity-dependent formation of perforated synapses in cultured hippocampal neurons. Eur J Neurosci 11:4241-4250.

Nusser Z, Lujan R, Laube G, Roberts JD, Molnar E, Somogyi P (1998) Cell type and pathway dependence of synaptic AMPA receptor number and variability in the hippocampus. Neuron 21:545-559.

Park M, Penick EC, Edwards JG, Kauer JA, Ehlers MD (2004) Recycling endosomes supply AMPA receptors for LTP. Science 305:1972-1975.

Park M, Salgado JM, Ostroff L, Helton TD, Robinson CG, Harris KM, Ehlers MD (2006) Plasticity-induced growth of dendritic spines by exocytic trafficking from recycling endosomes. Neuron 52:817-830.

Peters A, Palay SL, Webster HDF (1991) The fine structure of the nervous system. New York: Oxford.

Petralia RS, Wang YX, Wenthold RJ (2003) Internalization at glutamatergic synapses during development. Eur J Neurosci 18:3207-3217.

Petrini EM, Lu J, Cognet L, Lounis B, Ehlers MD, Choquet D (2009) Endocytic trafficking and recycling maintain a pool of mobile surface AMPA receptors required for synaptic potentiation. Neuron 63:92-105.

Popratiloff A, Weinberg RJ, Rustioni A (1998) AMPA receptors at primary afferent synapses in substantia gelatinosa after sciatic nerve section. Eur J Neurosci 10:3220-3230.

Rácz B, Blanpied TA, Ehlers MD, Weinberg RJ (2004) Lateral organization of endocytic machinery in dendritic spines. Nat Neurosci 7:917-918.

Santos SD, Carvalho AL, Caldeira MV, Duarte CB (2009) Regulation of AMPA receptors and synaptic plasticity. Neuroscience 158:105-125.

Shepherd JD, Huganir RL (2007) The cell biology of synaptic plasticity: AMPA receptor trafficking. Annu Rev Cell Dev Biol 23:613-643.

Takumi Y, Ramírez-León V, Laake P, Rinvik E, Ottersen OP (1999) Different modes of expression of AMPA and NMDA receptors in hippocampal synapses. Nat Neurosci 2:618-624.

Tao-Cheng JH (2006) Activity-related redistribution of presynaptic proteins at the active zone. Neuroscience 141:1217-1224.

Vissavajjhala P, Janssen WG, Hu Y, Gazzaley AH, Moran T, Hof PR, Morrison JH (1996) Synaptic distribution of the AMPA-GluR2 subunit and its colocalization with calcium-binding proteins in rat cerebral cortex: an immunohistochemical study using a GluR2-specific monoclonal antibody. Exp Neurol 142:296-312.

Wenthold RJ, Petralia RS, Blahos J II, Niedzielski AS (1996) Evidence for multiple AMPA receptor complexes in hippocampal CA1/CA2 neurons. J Neurosci 16:1982-1989.

Yudowski GA, Puthenveedu MA, Leonoudakis D, Panicker S, Thorn KS, Beattie EC, von Zastrow M (2007) Real-time imaging of discrete exocytic events mediating surface delivery of AMPA receptors. J Neurosci 27:11112-11121. 